\title{
Research on the Cultural Landscape of Xinjiang Section of the Silk Road
}

\author{
Dan Jiang \\ Academy of Fine Arts, Xinjiang Normal University, Urumqi, 830000, China
}

\begin{abstract}
Overlooking the section of the Silk Road in Xinjiang, as the largest span of linear, multi-dimensional cultural landscape, historical heritage and ecological corridor in Xinjiang, it is a huge heritage complex of human culture influencing on the natural landscape. This paper introduces the concept of cultural landscape corridor, taking into account the organic connection between landscape ecology and heritage protection, strengthens the understanding of local social structure and regional culture in Xinjiang, spatially integrates cultural landscape and linear historical relics.
\end{abstract}

Key words: section of the Silk Road in Xinjiang; cultural landscape corridor; value cognition and inheritance

\section{The Theoretical Framework of Cultural Landscape Corridor}

1.1 What cultural landscape means

The concept of cultural landscape was put forward by UNESCO in December 1992 and included in the World Heritage List. It refers to the rare and irreplaceable cultural landscape recognized by the World Heritage Committee and UNESCO. It refers to "the common works of nature and human beings" with universal social value. It includes architecture and landscape with aesthetic value and conscious design of human beings. It is a relic landscape that represents the past and has completed its evolution. It is traditional social landscape with evolutionary and sustainable development. It is also endangered architecture and landscape heritage associated with natural factors, religion, art and culture.

\subsection{Cultural corridor and heritage corridor}

The concept of "cultural corridor" originates from the theory of "heritage corridor" in the United States, and is closely related to the concept of "cultural route" in the field of world heritage protection. "Heritage corridor" is a theory and research method derived from the western regional heritage protection strategy. On account of the attribute of "corridor", it is usually emphasized as "heritage area" with linear characteristics. Heritage corridor is mainly composed of four parts, namely: road test green ecological corridor, historical heritage, interpretation system and footpath. In the new century, many scholars began to explore how to put the linear heritage theory into practice. Therefore, this paper puts forward new perspectives and new ideas for the protection and research of linear cultural heritage. Consequently, the concept of "cultural corridor" was born immediately.

1.3 Related research review home and abroad

The early research on corridor, route heritage and cultural landscape heritage at home and abroad can be traced back

Copyright (C) 2021 by author(s) and Frontier Scientific Research Publishing Inc.

This work is licensed under the Creative Commons Attribution International License (CC BY 4.0).

http://creativecommons.org/licenses/by/4.0/ 
to the 19th century. In the middle and late 20th century, with the promulgation of the Venice Charter and other international authoritative documents, the values and methodology of world-wide heritage protection were established, and the concept of "greenway" was introduced into the field of cultural heritage protection, and emerged a large number of representative works, such as Design with Nature. At the end of the 20th century, the concept of cultural landscape was formally put forward. In 1980s, the concept of cultural landscape was applied to the field of human geography in China. After this century, it began to extend to the comprehensive field. In recent years, cultural landscape heritage, route heritage and heritage corridor have entered the mainstream research field.

\section{Value Cognition of Xinjiang Section of the Silk Road}

2.1 The importance of Xinjiang in the construction of the core area of the Silk Road Economic Belt

The "Silk Road" was first proposed by German geographer Richthofen in 1877 in his book China. He named the "Silk Road" as "the Western transportation road between China and Central Asia and between China and India through silk trade from 114 B.C. to 127 A.D." The name was soon accepted and applied by the public and academic circles. Since ancient times, Xinjiang has been a fortress area where all ethnic groups in China meet, blend and communicate. Now, based on the concept of the ancient Silk Road, the Party Central Committee of CPC has put forward the strategic idea of jointly building the "New Silk Road" economic belt. At the same time, on June 22, 2014, China, Kazakhstan and Kyrgyzstan successfully declared the eastern section of the land Silk Road "Silk Road: road network of Chang'an-Tianshan Corridor" as a world cultural heritage and was successfully approved as the first one. The research on Xinjiang section of the silk road is of high value in many aspects, fields and disciplines.

\subsection{Heritage of Xinjiang section of the Silk Road collected and sorted}

First, the Xinjiang section of the silk road is a multi-dimensional cultural landscape with linear span features. Since the pre-Qin period, it has given birth to many ancient ethnic settlements. Secondly, it has the landscape features of the special arid region in the hinterland of Central Asia, it also has affected the development of human settlements in the western minority areas of China. Therefore, for such linear cultural heritage with large span, multi-dimensional, complex system and diverse branches, its research cannot stay at a single level of culture or heritage protection, but should absorb the regional historical context. However, according to the current research status, lacking integrity and continuity, and artificially severing the connection between ancient road heritage and heritage are the main problem, for the identity, status and value of any single cultural heritage on the ancient Silk Road are difficult to represent the display of the whole line. The Xinjiang section of the Silk Road is in line with the concept of cultural landscape heritage corridor. Therefore, it is hoped that this concept can build a more diversified heritage protection framework and witness the value of regional culture.

3. Practical Research on the Construction of Cultural Landscape Corridor in Xinjiang Section of the Silk Road

3.1 Promote the localization of the concept of cultural landscape corridor in Xinjiang section of the silk road

The concept of cultural landscape corridor provides new ideas and new methods for the protection of large-scale linear cultural heritage, however, according to the current output of academic achievements at home and abroad, the relevant research works within the geographical scope of the Xinjiang section of the Silk Road are rarer. Meanwhile, in view of the background differences of ideological origin and application object, it needs carrying on the localization adjustment.

First, we should cooperate with the experts to formulate a special identification standard on the recognition criterion of the Xinjiang section of the Silk Road, and clarify the overall occurrence status of heritage corridor resources. Secondly, 
we should further investigate the historical evolution and reality, deeply analyze the cultural connotation of each important heritage site. After that, we should establish comprehensive and scientific heritage archives for the protection of the cultural landscape corridor of the Xinjiang section of the silk road. Combined with the regional characteristics, the composition and attributes of each heritage site are investigated from archaeology, nationality, religion, folk custom, art, ecology and geography, so as to comprehensively summarize the heritage value of Xinjiang section of the Silk Road, and realize the localization of the concept of cultural landscape corridor.

3.2 Exploration of the practical methods for the construction of cultural landscape corridor in Xinjiang section of the Silk Road

Firstly, according to the geographical characteristics of the Silk Road, consider the problems in Xinjiang under the background of rapid urbanization, analyze the research whether suitable for the strategic planning of the "Silk Road Economic Belt", and determine the research route. Secondly, through a large number of literature research and field study, establish a relatively comprehensive and accurate understanding of the cultural landscape corridor in Xinjiang section,such as landscape ecological basis, historical evolution, regional development status, local social characteristics, etc. Thirdly, collect and sort out the material and intangible heritage elements, clarify the complex clues of each element, analyze the characteristics and value of each element at the macro, meso and micro levels, establish the analysis structure and index system, determine the weight of each index and establish the evaluation model, and then get the results. Besides, it is supposed to analyze the overall spatial pattern of cultural landscape corridor, and put forward the integration strategy of corridor space, such as: refining the spatial control points based on the evaluation results, combing the current binding force of each space and cultural landscape sequence. Finally, it is supposed to explore the protection and display of cultural landscape and heritage resources in Xinjiang. For example: to strengthen the corridor ecology and infrastructure construction, to protect the traditional culture of the settlement heritage site, to develop tourism with excellent cultural landscape resources.

\section{Conclusions}

The excellent historical and cultural heritage excavation and protection are listed on the national agenda with the implementation of the Great Western Development Strategy and "Belt and Road" development framework. We hope to further expand the development of the research on the construction of ethnic minority cultural resources in the west by introducing the concept of cultural landscape corridor.

\section{Conflicts of Interest}

The author declares no conflicts of interest regarding the publication of this paper.

\section{Acknowledgments}

Scientific Research Project of Colleges in Xinjiang Uygur Autonomous Region "Study on the Cultural Landscape Heritage Corridor of the Xinjiang Section of the Silk Road (20BYS149)".

\section{References}

[1] Sun Ge. (2006). A Study on Visual Meaning of Cultural-relics of the Heritage Corridor on Silk-road (Xinjiang Section). Journal of Xinjiang Normal University, (06): 91-95. 